\title{
Morphological predictors of slaughter yields using 3D digitizer and their use in a common carp breeding program
}

\author{
Prchal Martin 1? ${ }^{*}$, Kocour Martin ${ }^{1}$, Vandeputte Marc ${ }^{2,3}$, Kause Antti ${ }^{4}$, Vergnet Alain ${ }^{3}$, Zhao Jinfeng ${ }^{1}$, \\ Gela David ${ }^{1}$, Kašpar Vojtěch ${ }^{1}$, Genestout Lucie ${ }^{5}$, Bestin Anastasia ${ }^{6}$, Haffray Pierrick ${ }^{6}$, \\ Bugeon Jérôme ${ }^{7}$
}

1 University of South Bohemia in České Budějovice, Faculty of Fisheries and Protection of Waters, South Bohemian Research Center of Aquaculture and Biodiversity of Hydrocenoses, Zátiší 728/II, 389 25 Vodňany, Czech Republic

2 INRAE, GABI,, AgroParisTech, Université Paris-Saclay, 78350 Jouy-en-Josas, France

3 Ifremer, Chemin de Maguelone, F-34250 Palavas-les-Flots, France

${ }^{4}$ Natural Resources Institute Finland (Luke), Biometrical Genetics, Myllytie 1, FI-31600 Jokioinen, Finland

${ }^{5}$ LABOGENA-DNA, 78350 Jouy-en-Josas, France

${ }^{6}$ SYSAAF, LPGP/INRA, Campus de Beaulieu, F-35042 Rennes, France

7 INRAE, LPGP, 35000 Rennes, France

* Corresponding author : Martin Prchal, email address : mprchal@frov.jcu.cz

\begin{abstract}
:
Slaughter yields are traits of high interest especially for fish species sold in processed form like headless carcass or fillets, as well as with regard to increasing consumer preference for easy-to-prepare fish products. However, slaughter yields cannot be measured on live fish and thus their genetic improvement through mass selection is impossible. The usual alternatives are sib selection and/or indirect selection on correlated traits or morphological predictors of slaughter yields. In the present study, we assessed the possibility of using a combination of 3D digitized landmarks and ultrasound measurements in genetic improvement of slaughter yields in common carp. DNA - pedigreed market-size carp ( $n=1553$ fish) were produced from a partial factorial design of 20 dams and 40 sires. Morphological predictors were recorded in real-time using a 3D digitizer and ultrasound tomography, and combined by multiple linear regression to predict slaughter yields. The 3D model-predicted headless carcass and fillet yields explained $59 \%$ and $50 \%$, respectively, of the total phenotypic variation in slaughter yields. Genetic parameters of modelpredicted yields and of the best individual predictor (3D_P2 - ratio between abdominal fillet thickness E8 and external 3D ventral height) were similar or slightly lower when compared to previous 2D-based predictors (Prchal et al., 2018a, 2018b, 2018c). This was also the case for the expected genetic gain using indirect selection on the same simple predictor for fillet yield improvement $(0.48 \%$ fillet units for $3 \mathrm{D}$ vs. $0.52 \%$ for $2 \mathrm{D}$ ). $3 \mathrm{D}$ model-predicted yields and especially simple predictors thus have a solid potential for genetic improvement of slaughter yields in common carp. While they are not better than 2D predictors, they are much more convenient and faster to collect in the field, as they do not imply post-processing of images. These practical aspects should be taken into account in the future carp breeding program.
\end{abstract}




\section{Highlights}

- We studied combination of 3D digitized landmarks and ultrasound measurements. $>3 \mathrm{D}$ collection of morphological landmarks do not imply post processing of images. 3D models / predictors have a solid potential for genetic improvement of slaughter yields. Future carp breeding strategies have been suggested.

Keywords : fillet yields, 3D predictors, genetic parameters, indirect selection, breeding program 


\section{Introduction}

Fish traits defined as ratio of inputs and outputs (such as feed efficiency), or ratio of edible high-valued biomass relative to total fish weight (such as fillet yield) are fundamental efficiency-related traits for aquaculture operations. They are of high economic value (Kankainen et al., 2016), yet tricky to measure and include in : eeding programs (Haffray et al., 2013; Vandeputte et al., 2017; De Verdal et al., 2018; Fras' in $f \mathrm{t}$ al., 2018).

Slaughter yields are traits of high interest especis ily $f_{n}$ fish species sold in processed form like headless carcass or fillets (Kankainen è al., 2016), as well as with regard to increasing consumer preference for easy-to-pre pa f fish products (FAO, 2018). However, slaughter yields cannot be measured $c_{1}$ 've fish and consequently genetic improvement through mass selection on live breeding caı tidates is impossible. Similarly, the potential for

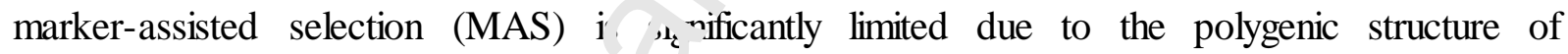
slaughter yields in fish species r. ai et al., 2015; Gonzalez-Pena et al., 2016; Yoshida et al., 2019). Yet, genomic selection, right be seen as future possibility for the genetic improvement of yields, as it allows a $\mathrm{l}$ ettes precision on sib-recorded traits (Yoshida et al., 2019). However, genomic selection is st:" oo costly and thus useful only for fish species with well-developed breeding programs e.g. Atlantic salmon (Salmo salar) or rainbow trout (Oncorhynchus mykiss) (Robledo et al, 2017) and for common carp (Cyprinus carpio or Cyprinus rubrofuscus) there is no available commercial SNP assay for such trait. Presently, edible part yields are commonly genetically improved by sib selection or by indirect selection via traits which are genetically correlated to slaughter yields (Kause et al., 2007; Gjedrem, 2010). Morphological predictors of slaughter yields based on non-destructive recording of external 2D landmarks and internal measures using ultrasound tomography could be an effective 
option to select for improved yields, as they can be used on the candidates without need for (costly) sib or genomic information (Cibert et al., 1999; Bosworth et al., 2001; Rutten et al., 2004; Van Sang et al., 2009; Haffray et al., 2013; Vandeputte et al., 2017; Prchal et al., 2018a).

Common carp is an important fish species in world aquaculture, though its breeding programs are mainly focused on utilization of heterotic effect by crossbreeding (Vandeputte, 2003; Janssen et al., 2017). This is the case despite the evidence for high genetic potential in using additive effect by genetic selection (Vandeputte et al ‘``4; Kocour et al., 2007;

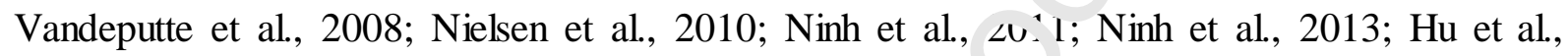
2017; Prchal et al., 2018b). In a previous study $w^{\text {th }}$ common carp, we investigated phenotypic and genetic potential of slaughter yield prea. ${ }^{*}$ ors based on $2 \mathrm{D}$ image analysis and ultrasound measurements, and their use in car sef ding programs (Prchal et al., 2018a). We observed a high accuracy of predictors $\mathrm{and}^{\mathrm{n}} \mathrm{d}$ favourable genetic relationship to the real yields. However, digitization of 2D landmar's requires post processing of images and cannot measure variation in body width. So, $t^{\prime}$ is method is at the same time incomplete and time consuming, which is a $\mathrm{m}_{\mathrm{n}}$ ior technical limitation for practical breeding programs. Alternatively, 3D collection of body landmarks could speed up digitization of potentially

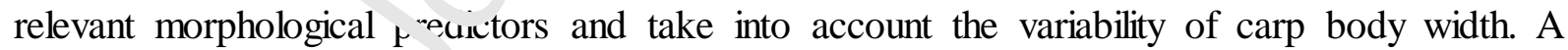
variety of 3D imagery systems have been used in pigs (Tillett et al., 2004), chickens (Mortensen et al., 2016) and cattle (Cappai et al., 2019; Le Cozler et al., 2019). Moreover, 3D digitizers like the MicroScribe (Solution Technologies Inc, Oella, MD, USA) are often used for research related to direct 3D morphological digitization of animal skeletons (Drake, 2011; Owen et al., 2014; Hanot et al., 2017). However, their potential for real time digitization of slaughter yield predictors directly on live fish has never been studied. 
In the present study, a 3D digitizer was used to collect landmarks on the fish body, instead of 2D digitizing from post-processing images. Thus, we aimed to i) determine the best morphological predictors of slaughter yields using combination of 3D landmarks and ultrasound imagery, ii) estimate genetic parameters of slaughter yield predictors and their association to the real yields, and iii) predict and compare expected genetic gain in response to selection for slaughter yield predictors based on 2D and 3D measurements and their practical implication in the carp breeding program.

\section{Material and Methods}

\subsection{Ethics statement}

The methodological protocol of the c. re. It study was approved by the expert committee of the Institutional Animal Ca $a^{2}$, nd Use Committee (IACUC) of the University of South Bohemia (USB), Faculty of Fisi sries and Protection of Waters (FFPW) in Vodňany according to the law on the protertior. $r \hat{f}$ animals against cruelty (Act no. 246/1992 Coll., ref. number 16OZ19179/2016-172 4). it market size the fish were humanely euthanized by trained person for subsequenı $n r$ scessing and slaughter yield evaluation.

\subsection{Production and rearing of experimental stock}

The fish are the same as those used in Prchal et al. (2018a). In short, an experimental stock of Amur mirror carp was produced at the Genetic Fishery Centre of University of South Bohemia (USB) in České Budějovice, Faculty of Fisheries and Protection of Waters (FFPW) in Vodňany, Czech Republic. Twenty dams and forty sires were propagated and crossed in a partial factorial design with four series of 5 dams and 10 sires. Each parental fish was DNA sampled (fin tissue) for later parentage assignment of the offspring fish. At the swimming 
stage, the experimental stock was created by pooling equal volumes of larvae. These larvae were released $\left(150,000\right.$ larvae. $\left.\mathrm{ha}^{-1}\right)$ to the prepared nursery ponds at the Klatovy fish farm and reared communally in ponds under a semi-intensive culture system typical for Central Europe. At one-year old, a random sample of 3000 fish from one pond (50\% survival, mean weight $\pm \mathrm{SD}=15.8 \pm 4.7 \mathrm{~g})$ was anesthetized with 2 -phenoxyethanol $(0.5 \mathrm{ml}$ per 11 of water $)$ and individually marked by PIT-Tags and DNA sampled for parentage assignment. The fish were harvested after the second growing period and the second overwintering. In October 2016 the stock (mean weight $=1910 \mathrm{~g}$ ) was harvested and mnvt. ${ }^{\top}$ to a storage pond before final traits recording at fish slaughter house of USB $\mathrm{F}^{\top} \boldsymbol{r}_{\mathbf{V}^{\prime}}$ in České Budějovice, Czech Republic. A total of 1622 individuals were humanely kilk ${ }^{-1}$ by a hit on the head and bled by cutting the gills according to the law on the protertis? of animals against cruelty (Act no. 246/1992).

\subsection{Final data collection}

Briefly, as previously reported $\sigma$ rchal et al., 2018a), 1622 fish were phenotyped for total length (TL), standard leng: ? ( $\mathrm{SL})$, body length $(\mathrm{BL})$, head length $(\mathrm{HL})$, body height $(\mathrm{BH})$ and body width (BWI) with in n-house electronic ruler (to nearest $0.1 \mathrm{~mm}$ ), and body weight (BW) was recorded $\mathrm{Wh}^{\mathrm{h}}$ an electronic scale (to nearest $0.1 \mathrm{~g}$ ). To describe the shape of the body, the head and the lateral line, a total of 15 coordinates (Figure 1.) of morphological points were digitized in 3 dimension (X,Y,Z) using a 3D digitizer (MicroScribe G2LX) connected to a computer, to which raw data were exported and stored in real time with a home-made software. The 11 landmarks and 4 semi landmarks (point 7, 10, 11 and 13) were chosen to be both easy to collect based on anatomical features (nose, operculum, fin, anus, lateral line) and evenly distributed all along the body to describe the whole body shape. 
Four muscular thicknesses from anterior (E4), intermediate (E5, E8) and posterior (E6) were collected using ultrasound imagery (Hospimedi LC1000, 7.5 MHz). For more details see Haffray et al. (2013) and Vandeputte et al. (2017) that preceded this study.

The total muscle fat content (\% Fat) was recorded using a Fish Fatmeter FM 692 (Distell Ltd., UK), using calibration option 'CARP - 1'. Biometrical indicators were calculated as Fulton's condition factor: $\mathrm{FC}=10^{5} *\left[\mathrm{BW}(\mathrm{g}) / \mathrm{SL}^{3}(\mathrm{~mm})\right]$, relative body height: $\mathrm{Re} \mathrm{BH}=$ BH / SL, and relative head length: RelHL = HL / SL. After biometric recordings, each fish was processed and the following body portions were weighea (to nearest $0.5 \mathrm{~g}$ ): head, left fillet, viscera, gonad, left fillet skin, half carcass, les. i'let ribs + trimmings, fins and scales. The weight of slaughter body parts and vertehra, axis was created by combining the previous body portions: headless carcass weight $\left[\mathrm{hl}-\mathrm{Ca}_{\mathrm{n}} \cdot \mathrm{sW}=\right.$ left fillet + left skin + left ribs and trimmings + half carcass], fillet weight with kiv. [FilletW $=$ (left fillet + left fillet skin) $*$ 2]. The slaughter yields expressed in $\%$ we e calculated as: headless carcass yield $\%[\% \mathrm{hl}-$ Carss $=($ hl-CarssW / BW $) * 100]$, anc fillet yield $[\%$ Fill $=($ left fillet + left skin $) * 2 / \mathrm{BW} *$ 100]. The natural logarithm was ca ated for the weight of each slaughtered part and regressed on the logarithm of hody weight to obtain growth-independent allometry residuals in order to provide genei- and phenotypic parameters giving reasonable estimates of predicted gains in slaug te ${ }^{+}$yield (Gunsett, 1984, 1987; Vandeputte et al., 2014). Therefore, for $\%$ headless carcass and $\%$ fillet yield, the surrogate traits are defined as log-log residuals (Logr) and termed as Logr_hl-Carss and Logr_Fill, respectively. In addition, logarithm of weight of all body portions was regressed on the logarithm of body weight to visualize body allometry (See Supplementary Material in Prchal et al., 2018a).

\subsection{D morphology and prediction models of slaughter yields}


The association of the variation in carp morphology to the variation in processing yields was analysed using the MorphoJ software (Klingenberg, 2011) as described previously in Prchal et al. (2018a) but using 3D landmarks coordinates instead of 2D. The wireframe visualization was performed on the side $(\mathrm{X}$ and $\mathrm{Y})$ and dorsal $(\mathrm{X}$ and $\mathrm{Z}$ ) view of the fish. The R Package 'geometry' was used to calculate areas and volumes from $3 \mathrm{D}$ coordinates raw data. A multiple linear regression using the reg.best function of the FactoMine $\mathrm{R}$ of $\mathrm{R}$ software package was performed using external morphology descriptors, ultrasound measurements and fat meter value as independent variables and the Logr_hl-Carss . nd Logr_Fill as dependent variables. List of predictors calculated and initially includ eu in the multiple linear regression are shown in Supplementary Table S1.

The best prediction model identification correspu nds to those with the highest $R^{2}$ and F-value. The models were used to calculate t'ke nr dicted yield values for each fish that are termed as Mod_hl-Carss for headless càna's yield and Mod_Fill for fillet yield. Models were cross validated using the crossval funcli $n$ of the bootstrap package in $\mathrm{R}$ software (Efron and Tibshirani, 1993).

\subsection{Parental allocation}

The 60 parents эı 2035 offspring were genotyped with 12 microsatellites loci at LABOGENA-DNA, the French laboratory for livestock genotyping (ISO 170025 accredited, Jouy-en-Josas, France). Parental allocation was performed using the AccurAssign software, applying a maximum-likelihood method (Boichard et al., 2014).

\subsection{Estimation of genetic parameters}

The data set was checked for potential outliers and the final genetic model was applied on 1553 individuals assigned to a single parental pair with a complete set of variables. 
Heritability $\left(h^{2}\right)$, phenotypic and genetic correlations ( $r_{\mathrm{p}}$, and $r_{\mathrm{g}}$, respectively) were estimated in multivariate mixed models using the restricted maximum likelihood method in DMU statistical software (Madsen and Jensen, 2013). The univariate (for heritability) and multivariate analysis (for genetic correlations) were on the following animal model:

$$
Y_{i j k}=\mu_{i}+\operatorname{sex}_{i j}+\operatorname{anim}_{i k}+e_{i j k}
$$

Where $Y_{i j k l}$ is the measured phenotypic value of each analyzed trait, $\mu_{i}$ is the overall mean for trait $i, \operatorname{sex}_{i j}$ is the fixed effect of $\operatorname{sex}(j=$ female, male, Inidentified sex $)$ for trait $i$, $\operatorname{anim}_{i k}$ is the random genetic effect of an animal $k$ vil. pedigree based on parentage assignment $(k=1,2, \ldots, 1553)$ for trait $i$, and $e_{i j k}$ is the andom residual. Heritability estimates were calculated as the ratio of additive genetic varianc $\left(V_{\mathrm{A}}\right)$ divided by the total phenotypic variance $\left(V_{\mathrm{P}}\right), h^{2}=V_{\mathrm{A}} / V_{\mathrm{P}}$. The likeliho $x_{\mathrm{a}}$ ro io test (LRT) was used for comparing the goodness of fit of two models (inc ' $\mathrm{d} d \mathrm{~g} g$ vs. excluding the animal genetic effect). The heritability estimates were considerea significant when the difference of additive genetic effect in -2Log-likelihood was highor 19.1 the threshold value for $p<0.05$ of a $\chi^{2}$ distribution with 1 degree of freedom (P. heirc and Bates, 2000). Genetic correlations were considered significant if $\left|r_{\mathrm{g}}\right|-\mid 1.96 \times$ S.I $\mid$ was higher than zero.

The genetic galı $(\Delta G)$ per generation were estimated using the breeder's equations from Falconer and McKay (1996) under a mass (MS), full-sib (FSS) and indirect (IS) selection responses for fillet yields. The theoretical genetic gain under mass selection (although it cannot be applied in practice) was calculated as $\Delta G_{M}=i h^{2} \sigma_{P}$, where $i$ is the selection intensity and $h^{2}$ and $\sigma_{\mathrm{P}}$ are the heritability and phenotypic standard deviation of the trait under selection, respectively. The response to selection of FSS was estimated as $\Delta G_{F S}=$ $\frac{i \times \sigma_{P} \times h^{2} \times n \times r}{\sqrt{n(1+(n-1) t)}}$, where $n$ is the number of sibs sampled per family $(n=10), r$ is the genetic correlation between sibs ( $r=0.5$ for full sibs) and $t$ is the phenotypic intra class correlation $(t$ 
$=r h^{2}$ ). The estimated genetic gain for indirect selection criteria was calculated as $\Delta G_{I}=i \times h_{1}$ $\mathrm{x} h_{2} \times r_{\mathrm{g}} \times \sigma_{P 2}$, where $\Delta G_{\mathrm{I}}$ is the estimated genetic gain on the target trait, $h_{1}$ and $h_{2}$ are the square roots of heritability of the indirect selection trait (on which selection is applied) and of the target trait, respectively, $r_{\mathrm{g}}$ is the genetic correlation estimated between the indirect trait and the target trait and $\sigma_{P 2}$ is the phenotypic standard deviation of the target trait. Finally, the real genetic gain was scaled back to the percent body weight units by multiplying $\Delta G$ by the real mean fillet yield in the present experimental stock (50\%). The selection intensities were set up of $10 \%$ and $30 \%$, with 10 sibs per family in FSS as the nost practical intensities for potential common carp breeding program.

\section{Results}

\subsection{Representation of families}

The 1553 fish used in this study arise sire varied from 14 to 79 , the average $w$ 's 39 . The number of progeny per dam varied from 25 to 128 , the average was 78 .

\subsection{Slaughter yields percenwor,}

Percentage of headless - aruass was $66 \% \pm 2.19$ and fillet yield was $50 \% \pm 1.95$. Such values were higher than usual values in common carp, most likely due to the specific experimental processing which was different from the commercial one but more valuable for studying the variation in the biological characteristics of the traits.

\subsection{D morphology and prediction equations of slaughter yields}

A graphical visualization of body and ventral part morphology associated to low (blue line) and high (red line) yield for Logr_hl-Carss and Logr_Fill is shown in Fig. 2. The greatest 
differences were observed on the abdominal part of the fish and on the head. Fish with higher yields present a lower ventral area, mainly under the dorsal fin, and also have a smaller head area.

The most informative morphological predictors $\left(3 \mathrm{D}_{-} \mathrm{P}_{1-7}\right)$ included into two prediction equations (3DMod_hl-Carss and 3DMod_Fill), and their $R^{2}$ and Fisher test values (F) are listed in Table 1. The selected 3D morphological landmarks (1-15) of carp body are shown on Figure 1.

Logr_hl-Carss was best predicted with a model comb. ing five simple predictors (3D_P $\left.2,3 D_{-} P_{3}, 3 D_{-} P_{4}, 3 D_{-} P_{5}, 3 D_{-} P_{6}\right) .3 D_{-} P_{2}=$ the $r$.uv ग abdominal fillet thickness (E8) to height between the lateral line and the aligned ventral $w$ int $7-8 ; 3 D_{-} P_{3}=3 \mathrm{D}$ area between 2-3-7-10-11-6 divided by 3D area 3-4-5-8-9-10-7; 3L_ $\mathrm{P}_{4}=$ volume between 2-3-7-10-11-6 divided by volume 3-4-5-8-9-10-7, 3D_P $\mathrm{P}_{5}=\mathrm{N}_{\mathrm{s}}^{\prime} \cdot \mathrm{h}$ at point 7 divided by width at point 4 and 3D_P $\mathrm{P}_{6}=$ width at point 10 divided by vir.h at point 4 . 3DMod_hl-Carss explains $59.2 \%$ $\left(\mathrm{R}^{2} \mathrm{CV}=58.8 \%\right)$ of total phenotypic vai $\cdot$ tion in Logr_hl-Carss.

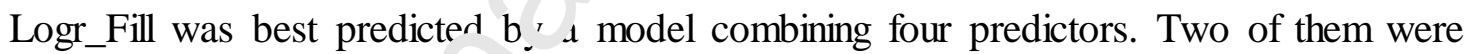
the same as for Logr_hl-Carss $\left(3 \mathbf{D}_{-} \mathbf{\mathbf { P } _ { 2 }}, \mathbf{3 D} \mathbf{P}_{\mathbf{6}}\right.$ ) and the different ones were $3 \mathbf{D}_{-} \mathbf{P}_{\mathbf{1}}=3 \mathrm{D}$ head

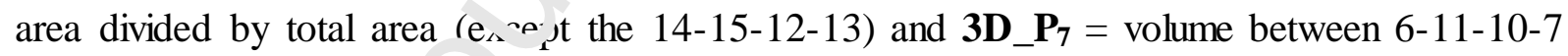
divided by volume \%1(1-y-8. 3DMod_Fill explains $49.6 \%\left(\mathrm{R}^{2} \mathrm{CV}=49.3 \%\right)$ of total phenotypic variation of Logr_Fill.

\subsection{Heritability estimates and genetic correlations}

Heritability estimates of the single predictors $\left(3 \mathrm{D}_{-} \mathrm{P}_{1}-3 \mathrm{D}_{-} \mathrm{P}_{7}\right)$, Logr slaughter yields (Logr_hl-Carss and Logr_Fill) and model-predicted slaughter yields (3DMod_hl-Carss and 3DMod_Fill) are given in Table 2. All heritabilities were significantly different from zero and achieved moderate to high values in the range of $0.29-0.66$. Heritability estimates and 
genetic correlations of yield-related phenotypes (BW, \% Fat, FC, RelBH, RelHL) are detailed in Prchal et al. 2018a.

The genetic correlations between individual predictors, Logr and 3DMod slaughter yields are listed in Table 2. 3D_P $\mathrm{P}_{1}$ was highly negatively correlated to 3D_P $6\left(r_{\mathrm{g}}=-0.70\right)$. 3D_P 3 and 3D_P $\mathrm{P}_{4}$ were highly correlated to each other $(0.98)$ as well as to $3 \mathrm{D}_{-} \mathrm{P}_{7}\left(r_{\mathrm{g}}=0.87\right.$, 0.85, respectively). Besides, $3 \mathrm{D}_{-} \mathrm{P}_{3}$ and $3 \mathrm{D}_{-} \mathrm{P}_{4}$ were also negatively genetically associated to 3D_P 5 and 3D_P 6 . Moreover, 3D_ $\mathrm{P}_{5}$ and 3D_P 6 were in moderately high genetic relationship $\left(r_{\mathrm{g}}=0.73\right)$. Only 3D_P $1,3 \mathrm{D}_{-} \mathrm{P}_{2}$ and $3 \mathrm{D}_{-} \mathrm{P}_{6}$ achieved favnuraı ${ }^{1 e}$ genetic relationship with Logr slaughter yields $\left(r_{\mathrm{g}}=|0.44-0.80|\right)$. Likewise, 35 nodel-predicted slaughter yields showed high genetic associations to the real yields to be s. $^{-}$dicted $\left(r_{\mathrm{g}}=0.84-0.88\right)$. Besides, residual weights to be predicted (Logr) as well as mou ${ }^{2}$-predicted (3DMod) slaughter yields were highly correlated to each other $\left(r_{\mathrm{g}}=0.84-9^{-}\right)$.

The genetic correlations of yiel -reated phenotypes to the most informative simple predictors and 3D model-predicted ylc.'s are presented in Table 3. The predictors 3D_ $\mathrm{P}_{1}$ and 3D_P $\mathrm{P}_{6}$ were in absolute values in th - same genetic pattern to all yield-related phenotypes. Thus, these predictors were ge: eticaily related to lower BW and FC (low correlation), RelBH (medium correlation) and Re.HL (strong correlation). Oppositely, selecting for such predictors might lead $n$ a slightly higher muscle fat $\left(\mathrm{r}_{\mathrm{g}}=|0.31-0.37|\right)$. 3D_P $\mathrm{P}_{2}$ was not significantly correlated to $\mathrm{BW}, \mathrm{FC}$ and RelBH but was also positively genetically associated to $\%$ Fat and negatively but at the edge of significance with RelHL. Regarding modelpredicted yields, genetic correlations were similar to $3 \mathrm{D}_{-} \mathrm{P}_{1}$ and $3 \mathrm{D} \mathrm{P}_{6}$ predictors but generally stronger for 3DMod_Fill especially in relation to BW, FC (insignificant for 3DMod_hl-Carss) and RelHL ( $r_{g}=-0.47$ vs. -0.67 , respectively).

\subsection{Expected genetic gain}


Expected genetic gains (Table 4.) were calculated for fillet yield and compared among mass (MS), full-sib (FSS) and indirect selection (IS) scheme using 3D model (3DMod_Fill) and 3D single predictors $\left(3 \mathrm{D}_{-} \mathrm{P}_{1}-3 \mathrm{D}_{-} \mathrm{P}_{7}\right)$.Genetic gain calculated for hypothetical mass selection (MS) was $0.70 \%$ (10\% selection intensity) and $0.46 \%$ (30\% selection intensity) per generation. Genetic gain for full-sib selection (FSS) with 10 sibs selected per family $(10 \%$ and $30 \%$ selection pressure) was slightly lower $(0.61 \%$ and $0.40 \%)$ than for MS. Estimated genetic gain achieved by indirect selection on the 3D model-predicted fillet yields (3DMod_Fill) was $0.65 \%$ and $0.43 \%$ for $10 \%$ and $30 \%$ celt.tion intensity, respectively. Genetic gains of the most effective 3D predictors (3D_P, :リ_P $\mathrm{P}_{2}$ and 3D_P ) ranged from $0.27 \%$ to $0.47 \%$. Other predictors showed much lowe values $(0.01 \%-0.19 \%)$. Relative genetic changes of yield-related traits were calculatsa tor fillet yield improvement using IS scheme (Supplementary Table S2).

\section{Discussion}

In the present study, we shov $e_{4}$ i) favourable phenotypic prediction accuracy of real slaughter yields, ii) moderate $\uparrow$ high heritability estimates of simple 3D predictors and 3D model-predicted yields; iii) su'ns genetic correlations of 3D predictors / models with the real slaughter yields suggesi $\cdot$ o wat the indirect selection could be strong enough to be used in genetic improvement of slaughter yields. Moreover, iv) potential genetic gain based on indirect selection of the 3D model (3DMod_Fil) was similar to that achieved by previously developed 2D model (2DMod_Fil) (Prchal et al., 2018a), however, best individual 3D predictor - 3D_P2 (E8/ 3D height in the ventral part) achieved less favorable genetic parameters than the same predictor in 2D - 2D_P2 (E8/ 2D height) (Prchal et al., 2018a). Still, 3D models / predictors have a solid potential for genetic improvement of slaughter yields in common carp as they are much faster evaluated on live breeding candidates, so that 
breeding program would be simple, efficient and sustainable, compared to previously used methods of external and internal measures (Cibert et al, 1999; Bosworth et al., 2001; Rutten et al., 2004; Van Sang et al., 2009; Haffray et al., 2013; Vandeputte et al., 2017; Prchal et al., 2018a).

The 3D model-predicted yields explained 59\% of the phenotypic variation in the real headless carcass yield, and $50 \%$ in real fillet yield. Accuracy to predict headless carcass yield using 3D was slightly lower than the accuracy in a previous study $(63 \%)$ that used $2 \mathrm{D}$ and ultrasound measurements (Prchal et al., 2018a). Yet, predici'n accuracy of 3D and ultrasound values for fillet yield prediction was equal $\uparrow, ? \mathrm{~V}$ and ultrasound recording in common carp (Prchal et al. 2018a) but higher than in ran.'ow trout (Haffray et al., 2013) and European sea bass (Vandeputte et al., 2017). So, mu rel-predicted yields using 2D or 3D showed almost similar phenotypic prediction as ard of real slaughter yields in common carp, explaining $49 \%$ - $63 \%$ of phenot, nic variation. Nevertheless, in common carp headless carcass yield was only predicted using three simple 2D predictors (Prchal et al., 2018a) but the best models of headless carcass, ie d used six predictors in rainbow trout (Haffray et al., 2013), nine predictors in Euro ${ }_{1}^{-}$an sea bass (Vandeputte et al., 2017) and five predictors in present study. It might have her, $\mathrm{n}$ caused by different digitization procedure between $2 \mathrm{D}$ and $3 \mathrm{D}$, as the previous $2 \mathrm{~L}$ sluuy in carp involved additional landmarks in the caudal part (Prchal et al., 2018a). So, comparison between 2D and 3D predictions might be affected by the number of landmarks digitized (15 in 3D vs. 20 in 2D) as more landmarks may lead to more precise measurements (especially areas) but on the other hand require more time for acquisition. Yet, the time required for post processing of morphological 2D landmarks and the lack of information on body width are the main limitations of $2 \mathrm{D}$ prediction. Moreover, Logr_Fill could be predicted only with 4 predictors using 3D instead of $52 \mathrm{D}$ predictors in Prchal et al. (2018a) and 6 predictors in Vandeputte et al. (2017), suggesting a simplified 
model of fillet yield using 3D digitization. 3D model-predicted yields have generally a strong prediction accuracy similar to $2 \mathrm{D}$ models, but $3 \mathrm{D}$ predictions are more practical for using in the field on a large sample of fish, due to the possibility to acquire data in real time. On the other hand, the initial cost of $3 \mathrm{D}$ digitizer is higher than collection of $2 \mathrm{D}$ images by camera $(10,000 €$ vs $1,000 €)$. However, when taking into account time required for post processing by one skilful person (almost one month), the return on this investment and practical use of such device is fast and clear. Briefly, during own recording it takes about $1.5 \mathrm{~min}$. of skilful person to get $3 \mathrm{D}$ coordinates and no further post-processing is rey.ired. To have $2 \mathrm{D}$ picture it takes about $1 \mathrm{~min}$. (correct positioning of fish to take in itormative picture, checking the result) and further $1 \mathrm{~min}$. to process the image later. $S_{0}, 2 \mathrm{D}$ is about $30 \mathrm{~s}$ slower than $3 \mathrm{D}$. However, the most important is that $3 \mathrm{D}$ coordinates $w_{\mathrm{h}}$ have immediately and can select the fish directly during one manipulation, meanwhile wh n using $2 \mathrm{D}$ we need to manipulate with all fish again later to select proper canc $\mathrm{la}^{+} \mathrm{s}$. It represents further time and more stress for fish (two manipulations, longer short-te. $\eta$ storage of fish in tanks). So, being able to select the fish during one manipulation is a $(\cdots$ ial task. However, both $2 \mathrm{D}$ and $3 \mathrm{D}$ model-predicted yields rely on precise coefficic 'ts lur linear combination of predictors. So, directly evaluating the potential of simple preci-tr is is therefore potentially much simpler for practical indirect selection.

Heritability estimates of 3D model-predicted yields were high ( 0.46 for hl-Carss and 0.56 for fillet) and slightly lower than the estimates predicted using $2 \mathrm{D}$ digitization $(0.48$, 0.63, respectively; Prchal et al., 2018a). Yet, the heritability estimates for 3D traits were higher when compared to other fish species (Van Sang et al., 2012; Haffray et al., 2013; Vandeputte et al., 2017). Predicted yields of both 2D and 3D models were strongly genetically correlated to the real yields $(0.84-0.88)$, showing their strong potential for indirect selection to improve edible part yields. It is also necessary to know the genetic correlations between the 
selected yield traits with other traits such as growth, body composition and fish welfare traits, as these traits may be changed indirectly by selection on yield traits. Some examples can be clearly seen in the previous studies that focused on improvement of yield that would indirectly lead to degradation of the flesh quality in cattle (Feitosa et al., 2017) and in common carp (Prchal et al., 2018c), pulmonary disease in broiler chicken (Hocking, 2010; Muir et al., 2014) or loss of flavour in tomatoes (Tieman et al., 2017).

In this study, we observed that selecting for 3D model-predicted yields would indirectly lead to several undesirable impacts similarly as in ca of $2 \mathrm{D}$-based predictors (Prchal et al., 2018a). Thus, such selection would mor wely increase muscle fat, slightly decrease body weight and cause fast change to an oblnny like body shape with a limited head size. A similar negative effect was also observed in rth ${ }^{*}$ studies as a genetic consequence of the selection for improved slaughter yields (Kc^cr $r$, al., 2007; Nguyen et al., 2010; Haffray et al., 2012; Janhunen et al., 2017; Fras $\eta f_{\imath}$ al., 2018). However, such changes could lead to negative fitness effects in a long-tern, breeding program (Fraslin et al, 2018). Therefore, these undesirable genetic relationshins $r$ ust be accounted for when breeding goal would be focused on increased slaughter ields.

Yields predicted bv itrait models are constructed from several simple individual predictors and the collt tion of all of them requires time and precision of measurements. Our results showed that recording of suitable individual predictors seems to be efficient for a simplified breeding program. Seven individual predictors from which the yield predictors were estimated achieved moderate to high heritability $(0.29-0.66)$. Three of them (3D_P $\mathrm{P}_{1}$, $\left.\mathrm{P}_{2}, \mathrm{P}_{6}\right)$ could be eventually used in a breeding program due to their high heritabilities $\left(h^{2}=\right.$ $0.44-0.66)$ and significant genetic correlations with the Logr yields $\left(r_{\mathrm{g}}=|0.44-0.80|\right)$. In addition, 3D_ $\mathrm{P}_{1}$ and $3 \mathrm{D}_{-} \mathrm{P}_{2}$ are the same morphological predictors as the previous 2D predictors 2D_P $\mathrm{P}_{1}$ and 2D_P $\mathrm{P}_{2}$ differing only in a way of digitization (Prchal et al., 2018a). 
The best simple predictor seems to be 3D_P $\mathrm{P}_{2}$ (ratio between abdominal fillet thickness - E8 and external ventral height measured between points 7-8 in 3D), similar to 2D predictor $\mathrm{P}_{2}$ in Prchal et al. (2018a) and ratio of E8 to E23 (depth of the peritoneal cavity) in rainbow trout (Haffray et al., 2013). 3D_P $\mathrm{P}_{2}$ is a highly heritable predictor, has genetic association to edible part yields showing its strong potential to be used in a breeding program as "quick-to measure" indirect selection criterion for improvement of yields in common carp. In addition, selection for that predictor would not lead to such significant decrease on head size and general body shape as in case of selection on 3D model predirtec yields. On the other hand, both yield models and simple predictors are positively ein ${ }^{+}$ically correlated to muscle fat. Hence, a selection program focused on improvement nt '17ughter yields should check muscle lipid level and eventual change of feeding strategy wn'ld be necessary to keep high flesh

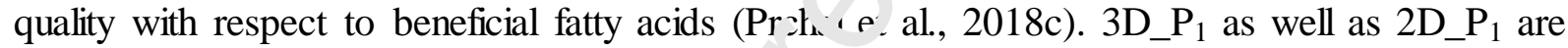
defined as a ratio between head area tc to $\downarrow l$ body area with a negative genetic correlation to the real yields. Nevertheless, 3D_P $\mathrm{P}_{1}$ has a higher heritability than $2 \mathrm{D}_{-} \mathrm{P}_{1}\left(h^{2}=0.50\right.$ vs. 0.34 in 2D) and is also more correlated tr $\mathrm{L}_{\mathrm{\sigma}}$ yields $\left(r_{\mathrm{g}}=-0.54--0.59\right.$ vs. $-0.52--0.57$ in $\left.2 \mathrm{D}\right)$. 3D_P 6 (width at point 10 divis ed $\llcorner y$ width at point 4) was a new simple predictor with very high heritability (0.66) and $f_{9 v}$ surable genetic relationship to the slaughter yields $(0.44$ 0.58). However, selecu $\eta$ vased on these simple predictors could indirectly lead to several unwanted changes similarly like in case of selection on 2D/3D yield models already discussed above. Therefore, the use of predictors in a selection index including shape and fat content would be a suitable breeding scenario to avoid a negative impact of indirect selection for fillet yield on other traits of interest.

The calculations of expected genetic gains showed that 3D model-predicted yields or simple predictors are interesting candidates for a selection program. The highest genetic gain in fillet yield was observed by hypothetical mass selection (MS) on real fillet yield $(0.70 \%$ for 
$10 \%$ selection intensity). Such selection method is typically used as benchmark value to compare with other selection schemes, though it is not possible in the breeding program. Slightly lower genetic gain was observed using sib selection (FSS) on real fillet yield, a typical approach applied for traits requiring destructive recording (slaughter yields, meat quality) or disease resistance (Gjedrem, 2010). However, costs for FSS are higher and in our case cover also parentage assignment and processing costs of sib groups. Thus, our work confirm that indirect selection may be an interesting alternative to establish a lower cost and sustainable breeding program. Indeed, indirect selection on 3I) . odel-predicted fillet yields showed even better genetic progress than FSS. This $\mathrm{r}^{\prime} \mathrm{su}^{-}$was also in accordance with previous 2D fillet model yields (Prchal el., 2018a) that shu'ved the same expected response to selection. However, main limitations of using model $\mathrm{p}_{\mathbf{1}}$-dicted yields in a breeding program have been already discussed above. Expecte' senetic gains of simple predictors were generally lower than from $2 \mathrm{D}$ or $3 \mathrm{D}$ fille yield models but still significant enough to be included in a selection program. 3D_ $\mathrm{F}_{1}$ achieved a better gain than the same predictor in 2D $(0.41 \%$ vs. $0.33 \%)$. Alternatively, nev SD_P $_{6}$ predictor was better for genetic progress than 3D_P $\mathrm{P}_{1}$ but these predictors ar: gentically related to unfavourable consequences that might be considered as reasonable bl'ns,cal limits in a long-term breeding program. The best genetic progress using a simp $n$ predictor would be obtained by 3D_P $\mathrm{P}_{2}(0.48 \%)$, similarly to our previous 2D experiment where the gain was even higher (0.52\%) (Prchal et al., 2018a). Moreover, this predictor is more favourably genetically connected to other phenotypes and easy and especially quick to record in the field and thus a very practical simple trait for indirect selection of slaughter yields in common carp.

\section{Conclusions}


The accuracy of the phenotypic prediction of slaughter yields by $3 \mathrm{D}$ models is high and almost similar to $2 \mathrm{D}$ prediction models. Likewise, expected genetic progress to be obtained by selection on model-predicted yields and on the best individual predictor (3D_ $\left.\mathrm{P}_{2}\right)$ were similar or only slightly lower when compared to the 2D-based models and the best $2 \mathrm{D}$ simple predictor (Prchal et al., 2018). In conclusion, model-predicted yields and especially simple 3D predictors have a solid potential for genetic improvement of slaughter yields in common carp. While such predictors are not better than $2 \mathrm{D}$ predictors, they are much more convenient and faster to collect in the field, as they do not imnly nost-processing of images. These practical aspects should be taken into account in th $i^{\text {th }}$ ture carp breeding program and we expect to verify the applicability of such predirtor in a practical selection response experiment.

\section{Competing interests}

The authors declare that they rave no competing interests.

\section{Authors' contributions}

MP, DG, and MA stablished and reared the experimental stock. MP and MK PIT tagged and sampled the DNA from finclips. PH and MV provided the methodology and equipment. MP, JB, MV, AV, JZ, DG, AB, VK, and MK shared on final trait recordings. $\mathrm{AK}$ introduced MP to the quantitative genetic analysis. JB carried out 3D digitization and the phenotypic prediction of slaughter yields. LG performed the DNA extractions and parentage assignment. MP estimated the genetic parameters. All authors contributed to drafting the manuscript and approved the final version.

\section{Acknowledgements}


This study was supported by European Union's Seventh Framework Programme

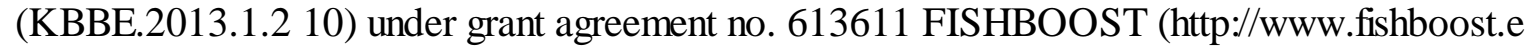
u/), Ministry of Education, Youth and Sports of the Czech Republic - project „CENAKVA“(LM2018099) and Biodiverzita (CZ.02.1.01/0.0/0.0/16_025/0007370), the Grant Agency of the University of South Bohemia in České Budějovice (project no. 097/2019/Z) and Ministry of Agriculture - project of the Czech NAAR (NAZV) no. QK1910430. 


\section{References}

Boichard, D., Barbotte, L., Genestout, L., 2014. AccurAssign, software for accurate maximumlikelihood parentage assignment., Presented at 10th WCGALP. 2014, Vancouver, Canada; available from: https://asas.org/docs/default-source/wcgalp posters/397_paper_9157_manuscript_448_0.pdf?sfvrsn=2.

Bosworth, B., Holland, M., Brazil, B., 2001. Evaluation of ultrasound imagery and body shape to predict carcass and fillet yield in farm-raised catfish. J. Anim. Sci. 79, 1483-1490. https://doi.org/10.2527/2001.7961483x.

Cappai, M.G., Gambella, F., Piccirilli, D., Rubiu, N.G., Dimauro, C., Pazzona, A.L., Pinna, W., 2019. Integrating the RFID identification system for Charolaise breeding bulls with 3D imaging for virtual archive creation. PeerJ Computer Science. 5, e17 7 . http://doi.org/10.7717/peerjcs.179.

Cibert, C., Fermon, Y., Vallod, D., Meunier, F.J., 1999. Morp' ='ng, al screening of carp Cyprinus carpio: relationship between morphology and fillet ielı. Aquat. Living Resour. 12, 1-10. https://doi.org/10.1016/S0990-7440(99)800u. -6.

De Verdal, H., Komen, H., Quillet, E., Chatain, B., Allai, r., Benzie, J.A., Vandeputte, M., 2018. Improving feed efficiency in fish using selectiv/ breeding: a review. Rev. Aquacult. 10, 833851. https://doi.org/10.1111/raq.12202.

Drake, A.G., 2011. Dispelling dog dogma ar investigation of heterochrony in dogs using 3D geometric morphometric analys: of skull shape. Evol Dev. 13, 204-213. https://doi.org/10.1111/j.1525-: 12 X.2011.00470.x.

Efron, B., Tibshirani, R., 1993. An Intro ' $U$ tı,$n$ to the Bootstrap. Chapman \& Hall, New York.

Falconer, D.S., MacKay, T.F.C., 19: Introduction to Quantitative Genetics. fourth ed.Longman Scientific \& Technical, Haı '?w, UK, pp. 464.

FAO, 2018. Fishery and aqu--1/Li.e statistics [aquaculture production (Quantities and values) 19502014] (Fish(tai'). In: FAO fisheries and aquaculture department.

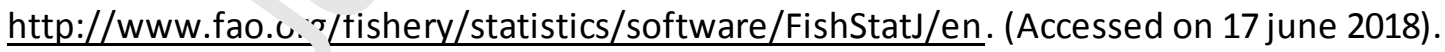

Feitosa, F.L.B., Olivieri, B.F., Aboujaoude, C., Pereira, A.I.S.C., de Lemos, M.V.A., Chiaia, H.L.J., Berton, M.P., Peripolli, E., Ferrinho, A.M., Mueller, L.F., Mazalli, M.n.R., de Albuquerque, L.G.o., de Oliveira, H.N., Tonhati, H., Espigolan, R., Tonussi, R.L., de Oliveira Silva, R.M., Gordo, D.G.M., Magalhães1, A.F.c.B., Aguilar, I., Baldi, F., 2017. Genetic correlation estimates between beef fatty acid profile with meat and carcass traits in Nellore cattle finished in feedlot. J. Appl. Genet. 58, 123-132. https://doi.org/10.1007/s13353-016-0360-7.

Fraslin, C., Dupont-Nivet, M., Haffray, P., Bestin, A., Vandeputte, M., 2018. How to genetically increase fillet yield in fish: New insights from simulations based on field data. Aquaculture. 486, 175-183. https://doi.org/10.1016/i.aquaculture.2017.12.012.

Gjedrem, T., 2010. The first family-based breeding program in aquaculture. Rev. Aquacult. 2, 2-15. https://doi.org/10.1111/j.1753-5131.2010.01011.x. 
Gonzalez-Pena, D., Gao, G., Baranski, M., Moen, T., Cleveland, B.M., Kenney, P.B., Vallejo, R.L., Palti, Y., Leeds, T.D., 2016. Genome-wide association study for identifying loci that affect fillet yield, carcass, and body weight traits in rainbow trout (Oncorhynchus mykiss). Front. Genet. 7, 203. https://doi.org/10.3389/fgene.2016.00203.

Gunsett, F., 1984. Linear index selection to improve traits defined as ratios. J. Anim. Sci. 59, 11851193. https://doi.org/10.2527/jas1984.5951185x.

Gunsett, F., 1987. Merit of utilizing the heritability of a ratio to predict the genetic change of a ratio. J. Anim. Sci. 65, 936-942. https://doi.org/10.2527/jas1987.654936x.

Haffray, P., Bugeon, J., Pincent, C., Chapuis, H., Mazeiraud, E., Rossignol, M.-N., Chatain, B., Vandeputte, M., Dupont-Nivet, M., 2012. Negative genetic correlations between production traits and head or bony tissues in large all-female rainbrw trout (Oncorhynchus mykiss). Aquaculture. 368, 145-152. https://doi.org/10.1016/j.aquacui' 'ure.2012.09.023.

Haffray, P., Bugeon, J., Rivard, Q., Quittet, B., Puyo, S., Allamelo. '.M., Vandeputte, M., DupontNivet, M., 2013. Genetic parameters of in-vivo predicti on o carcass, head and fillet yields by internal ultrasound and 2D external imagery in larg raınow trout (Oncorhynchus mykiss).

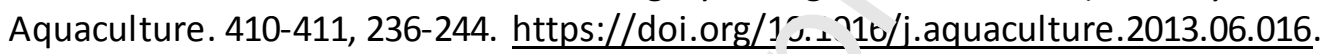

Hanot, P., Guintard, C., Lepetz, S., Cornette, R., 2017. Ider' 'ifying domestic horses, donkeys and hybrids from archaeological deposits: a $: 0 \mathrm{n}$ >rphological investigation on skeletons. J. Archaeol. Sci. 78, 88-98. https://doi.org/1 J.i-1 v/j.jas.2016.12.002.

Hocking, P., 2010. Developments in poult, , enetic research 1960-2009. Br. Poult. Sci. 51, 44-51. https://doi.org/10.1080/000716 2 8.2010. 07333 .

Hu, X., Li, C., Shang, M., Ge, Y., Jia, Z., V ar ૬, S., Zhang, Q., Shi, L., 2017. Inheritance of growth traits in Songpu mirror carp (Cyprin' _ _ ca.; , io L.) cultured in Northeast China. Aquaculture. 477, 1-5. http://dx.doi.org/10.1016/i. ${ }^{\text {qquaculture.2017.04.031. }}$

Janhunen, M., Nousiainen, A., Ko_'inen, H., Vehviläinen, H., Kause, A., 2017. Selection strategies for controlling muscle lipi -1 .ontent recorded with a non-destructive method in European whitefish, Corego ius I' 'varetus. Aquaculture. 481, 229-238.

https://doi.org/^? 1u^6/j.aquaculture.2017.09.016.

Janssen, K., Chavanne, H., Berentsen, P., Komen, H., 2017. Impact of selective breeding on European aquaculture. Aquaculture. 472, 8-16. https://doi.org/10.1016/j.aquaculture.2016.03.012.

Kankainen, M., Setälä, J., Kause, A., Quinton, C., Airaksinen, S., Koskela, J., 2016. Economic values of supply chain productivity and quality traits calculated for a farmed European whitefish breeding program. Aquacult. Econ. Manage. 20, 131-164.

https://doi.org/10.1080/13657305.2016.1155961.

Kause, A., Paananen, T., Ritola, O., Koskinen, H., 2007. Direct and indirect selection of visceral lipid weight, fillet weight, and fillet percentage in a rainbow trout breeding program. J. Anim. Sci. 85, 3218-3227. https://doi.org/10.2527/jas.2007-0332.

Klingenberg, C.P., 2011. MorphoJ: an integrated software package for geometric morphometrics. Mol. Ecol. Resour. 11, 353-357. https://doi.org/10.1111/j.1755-0998.2010.02924.x. 
Kocour, M., Mauger, S., Rodina, M., Gela, D., Linhart, O., Vandeputte, M., 2007. Heritability estimates for processing and quality traits in common carp (Cyprinus carpio L.) using a molecular pedigree. Aquaculture. 270, 43-50. https://doi.org/10.1016/j.aquaculture.2007.03.001.

Le Cozler, Y., Allain, C., Caillot, A., Delouard, J., Delattre, L., Luginbuhl, T., Faverdin, P., 2019. Highprecision scanning system for complete 3D cow body shape imaging and analysis of morphological traits. Comput. Electron. Agric. 157, 447-453.

https://doi.org/10.1016/j.compag.2019.01.019.

Madsen, P., Jensen, J., 2013. DMU version 6, http://dmu.agrsci.dk/DMU/Doc/Current/dmuv6 guide. 5.2.pdf (Accessed on December 2017).

Mortensen, A.K., Lisouski, P., Ahrendt, P., 2016. Weight prediction of broiler chickens using 3D computer vision. Comput. Electron. Agric. 123, 319-326.

https://doi.org/10.1016/j.compag.2016.03.011.

Muir, W.M., Cheng, H.-W., Croney, C., 2014. Methods to addres nr ultry robustness and welfare issues through breeding and associated ethical c insic erations. Front. Genet. 5, 407. https://doi.org/10.3389/fgene.2014.00407.

Nguyen, N.H., Ponzoni, R.W., Yee, H.Y., Abu-Bakar, K.R., ' 'arr zah, A., Khaw, H.L., 2010. Quantitative genetic basis of fatty acid composition in the GIF, strain of Nile tilapia (Oreochromis niloticus) selected for high growth. Aquaculture. 30؟ 6',-74.

https://doi.org/10.1016/j.aquaculture.2n 0.ᄂ2.J34.

Nielsen, H.M., Ødegård, J., Olesen, I., Gjerdt, R , Ardo, L., Jeney, G., Jeney, Z., 2010. Genetic analysis of common carp (Cyprinus carpio) straı. s. I: Genetic parameters and heterosis for growth $\begin{array}{lllll}\text { traits and survi. } 7 . \quad \text { Aquaculture. } & \text { 14-21. }\end{array}$ https://doi.org/10.1016/j.aqui cu $\underline{\text { ire.2010.03.016. }}$

Ninh, N.H., Ponzoni, R.W., Nguyen, . '.H., Woolliams, J.A., Taggart, J.B., McAndrew, B.J., Penman, D.J., 2011. A comparison of $c_{i} n$ munal and separate rearing of families in selective breeding of common carp (Cyprinus c rrpio): Estimation of genetic parameters. Aquaculture. 322-323, 39-

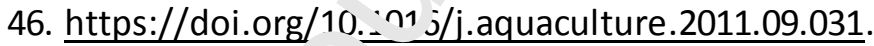

Ninh, N.H., Ponzoni, R.W., N zuyen, N.H., Woolliams, J.A., Taggart, J.B., McAndrew, B.J., Penman, D.J., 2013. A comparisor of communal and separate rearing of families in selective breeding of common carp (Cyprinus carpio): Responses to selection. Aquaculture. 408-409, 152-159. https://doi.org/10.1016/j.aquaculture.2013.06.005.

Owen, J., Dobney, K., Evin, A., Cucchi, T., Larson, G., Vidarsdottir, U.S., 2014. The zooarchaeological application of quantifying cranial shape differences in wild boar and domestic pigs (Sus scrofa) using 3D geometric morphometrics. J. Archaeol. Sci. 43, 159-167. https://doi.org/10.1016/j.jas.2013.12.010.

Pinheiro, J.C., Bates, D.M., 2000. Mixed-Effects Models in S and S-PLUS. Springer-Verlag, New York.

Prchal, M., Bugeon, J., Vandeputte, M., Kause, A., Vergnet, A., Zhao, J., Gela, D., Genestout, L., Bestin, A., Haffray, P., Kocour, M., 2018a. Potential for genetic improvement of the main slaughter yields in common carp with in vivo morphological predictors. Front. Genet. 9, 283. https://doi.org/10.3389/fgene.2018.00283. 
Prchal, M., Kause, A., Vandeputte, M., Gela, D., Allamelou, J.M., Girish, K., Bestin, A., Bugeon, J., Zhao, J., Kocour, M., 2018b. The genetics of overwintering performance in two-year old common carp and its relation to performance until market size. PLoS ONE. 13, e0191624. https://doi.org/10.1371/journal.pone.0191624.

Prchal, M., Vandeputte, M., Gela, D., Doležal, M., Buchtová, H., Rodina, M., Flajšhans, M., Kocour, M., 2018c. Estimation of genetic parameters of fatty acids composition in flesh of market size common carp (Cyprinus carpio L.) and their relation to performance traits revealed that selective breeding can indirectly affect flesh quality. Czech J. Anim. Sci. 63, 280-291. https://doi.org/10.17221/30/2018-CJAS.

Robledo, D., Palaiokostas, C., Bargelloni, L., Martínez, P., Houston, R., 2017. Applications of genotyping by sequencing in aquaculture breeding and genetics. Reviews in Aquaculture. 0 , 1-13. https://doi.org/10.1111/raq.12193

Rutten, M.J., Bovenhuis, H., Komen, H., 2004. Modeling fillet trait Da. ed on body measurements in three Nile tilapia strains (Oreochromis niloticus L.), Aquaculture. 231, 113-122. https://doi.org/10.1016/j.aquaculture.2003.11.002.

Tieman, D., Zhu, G., Resende, M.F., Lin, T., Nguyen, C., B' $e s$, ग., Rambla, J.L., Beltran, K.S.O., Taylor, M., Zhang, B., 2017. A chemical genetic roadmar to mproved tomato flavor. Science. 355 , 391-394. https://doi.org/10.1126/science.aal 15 r,6.

Tillett, R., McFarlane, N., Wu, J., Schofield, C., Ju X., U... Dert, J., 2004. Extracting morphological data from 3D images of pigs. Proceed'ng. or the international conference on agricultural engineering, AgEng 2004, Leuven, b、 'r,lum. Citeseer, pp. 492-493.

Tsai, H.Y., Hamilton, A., Guy, D.R., Tinc. A.E., Bishop, S.C., Houston, R.D., 2015. The genetic architecture of growth and fill $t \mathrm{t} / \mathrm{r}$ i^s in farmed Atlantic salmon (Salmo salar). BMC Genet. 16, 51. https://doi.org/10.11 ב 1 / 1 - $863-015-0215-y$.

Van Sang, N., Klemetsdal, G., Øì sgårù, J., Gjøen, H.M., 2012. Genetic parameters of economically important traits recordec it a given age in striped catfish (Pangasianodon hypophthalmus). Aquaculture. 344, 87-8; $r_{\text {.tps://doi.org/10.1016/j.aquaculture.2012.03.013. }}$.

Van Sang, N., Thomasseı., Nı., Klemetsdal, G., Gjøen, H.M., 2009. Prediction of fillet weight, fillet yield, and fillet fat $f$, $r$ live river catfish (Pangasianodon hypophthalmus). Aquaculture. 288, 166-171. https://doi.org/10.1016/j.aquaculture.2008.11.030.

Vandeputte, M., 2003. Selective breeding of quantitative traits in the common carp (Cyprinus carpio): a review. Aquat. Living Resour. 16, 399-407. https://doi.org/10.1016/S0990-7440(03)00056$\underline{1 .}$

Vandeputte, M., Garouste, R., Dupont-Nivet, M., Haffray, P., Vergnet, A., Chavanne, H., Laureau, S., Ron, T.B., Pagelson, G., Mazorra, C., 2014. Multi-site evaluation of the rearing performances of 5 wild populations of European sea bass (Dicentrarchus labrax). Aquaculture. 424, 239248. https://doi.org/10.1016/j.aquaculture.2014.01.005.

Vandeputte, M., Kocour, M., Mauger, S., Dupont-Nivet, M., De Guerry, D., Rodina, M., Gela, D., Vallod, D., Chevassus, B., Linhart, O., 2004. Heritability estimates for growth-related traits using microsatellite parentage assignment in juvenile common carp (Cyprinus carpio L.). Aquaculture. 235, 223-236. https://doi.org/10.1016/j.aquaculture.2003.12.019. 
Vandeputte, M., Kocour, M., Mauger, S., Rodina, M., Launay, A., Gela, D., Dupont-Nivet, M., Hulak, M., Linhart, O., 2008. Genetic variation for growth at one and two summers of age in the common carp (Cyprinus carpio L.): Heritability estimates and response to selection. Aquaculture. 277, 7-13. https://doi.org/10.1016/j.aquaculture.2008.02.009.

Vandeputte, M., Puledda, A., Tyran, A.S., Bestin, A., Coulombet, C., Bajek, A., Baldit, G., Vergnet, A., Allal, F., Bugeon, J., Haffray, P., 2017. Investigation of morphological predictors of fillet and carcass yield in European sea bass (Dicentrarchus labrax) for application in selective breeding. Aquaculture. 470, 40-49. https://doi.org/10.1016/j.aquaculture.2016.12.014.

Yoshida, G.M., Lhorente, J.P., Correa, K., Soto, J., Salas, D., Yáñez, J.M., 2019. Genome-wide association study and cost-efficient genomic predictions for growth and fillet yield in Nile tilapia (Oreochromis niloticus). G3: Genes, Genomes, Genetics, 9, 2597-2607. https://doi.org/10.1534/g3.119.400116. 


\section{Tables}

Table 1: Multiple linear regression models to predict Logr headless carcass and Logr fillet yields in common carp including predictors characteristics, regression statistics $R^{2}, \mathrm{~F}-$ Fisher test value and prediction equations.

\begin{tabular}{|c|c|}
\hline Headless carcass yield 3D model & Predictor characteristics \\
\hline 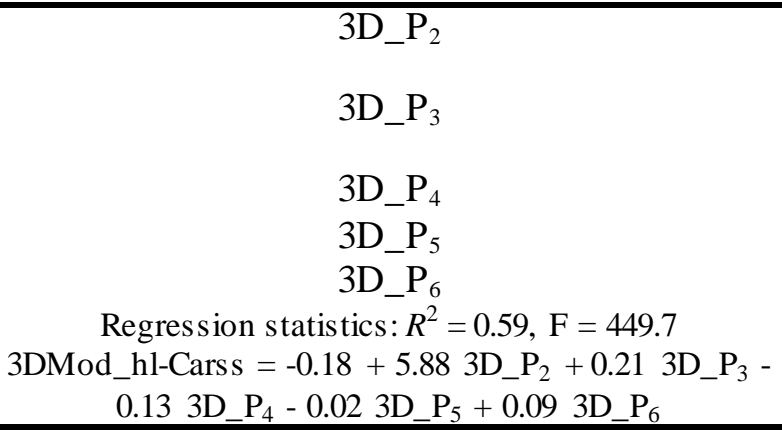 & $\begin{array}{l}\text { Ratio between E8 and 3D height between points 7-8 } \\
\text { 3D area between 2-3-7-10-11-6 divided by area 3-4-5- } \\
\text { 8-9-10-7 } \\
\text { Volume between 2-3-7-10-11-6 divided by volume 3- } \\
4-5-8-9-10-7 \\
\text { Width at point } 7 \text { divided by width at point } 4 \\
\text { Width at point } 10 \text { divided by width at point } 4\end{array}$ \\
\hline Fillet yield 3D model & euctor characteristics \\
\hline $\begin{array}{c}\text { 3D_P } \\
\text { 3D_P } P_{2} \\
\text { 3D_P6 } \\
\text { 3D_P } P_{7} \\
\text { Regression statistics: } R^{2}=0.49, \mathrm{~F}=381.9 \\
\text { 3DMod_Fill }=-0.10-0.463 \mathrm{D} \_\mathrm{P}_{1}+5.88 \text { 3D_P } \\
0.113 \mathrm{D} \_\mathrm{P}_{6}+0.023 \mathrm{D} \_\mathrm{P}_{7}\end{array}$ & 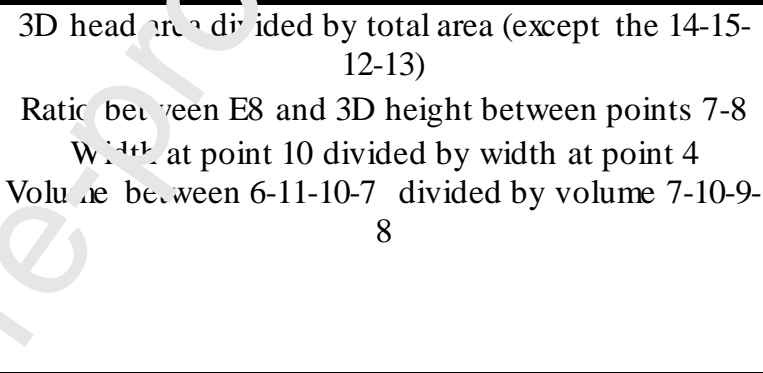 \\
\hline
\end{tabular}


Table 2: Heritability ( \pm standard error) estimates (diagonal) in bold, phenotypic (below the diagonal) and genetic correlations \pm standard error (above the diagonal) in common carp for simple predictors $\left(3 \mathrm{D}_{-} \mathrm{P}_{1}-3 \mathrm{D}_{-} \mathrm{P}_{7}\right)$, log-log residuals (Logr) of slaughter yields and 3D models (Mod) to predict slaughter yields.

\begin{tabular}{|c|c|c|c|c|c|c|c|c|c|c|c|}
\hline & 3D_P 1 & 3D_P 2 & 3D_P ${ }_{3}$ & 3D_P 4 & 3D_P 5 & 3D_P 6 & 3D_P 7 & $\begin{array}{c}\text { Logr_hl- } \\
\text { Carss }\end{array}$ & Logr_Fill & $\begin{array}{l}\text { 3DMod_hl- } \\
\text { Carss }\end{array}$ & 3DMod_Fil \\
\hline 3D_P ${ }_{1}$ & $\begin{array}{c}0.50 \pm \\
0.08\end{array}$ & $-0.25 \pm 0.15$ & $0.27 \pm 0.15$ & $0.38 \pm 0.14$ & $-0.46 \pm 0.12$ & $-0.70 \pm 0.08$ & $0.17 \pm 0.16$ & $\begin{array}{c}-0.54 \pm \\
0.11\end{array}$ & $\begin{array}{c}-0.59 \pm \\
0.10\end{array}$ & $-0.47 \pm 0.12$ & $-0.72 \pm 0.08$ \\
\hline 3D_P ${ }_{2}$ & -0.07 & $0.44 \pm 0.08$ & $-0.02 \pm 0.16$ & $-0.09 \pm 0.16$ & $-0.25 \pm 0.15$ & $0.18 \pm 0.15$ & $0.12 \pm 0.16$ & $\begin{array}{c}0.80 \pm \\
0.06\end{array}$ & $\begin{array}{c}0.73 \pm \\
0.08\end{array}$ & $0.93 \pm 0.02$ & $0.80 \pm 0.06$ \\
\hline 3D_P ${ }_{3}$ & 0.15 & 0.25 & $0.39 \pm 0.07$ & $0.98 \pm 0.01$ & $-0.39 \pm 0.14$ & $-0.41 \pm 0.13$ & $0.8^{5} \pm 7.6$ & $\begin{array}{c}-0.10 \pm \\
0.16\end{array}$ & $\begin{array}{c}-0.19 \pm \\
0.16\end{array}$ & $-0.07 \pm 0.16$ & $-0.22 \pm 0.15$ \\
\hline 3D_P 4 & 0.17 & 0.21 & 0.95 & $0.42 \pm 0.08$ & $-0.44 \pm 0.13$ & $-0.51 \pm 0 \quad 2$ & c $85 \pm 0.05$ & $\begin{array}{c}-0.20 \pm \\
0.16\end{array}$ & $\begin{array}{l}-0.29 \pm \\
0.15\end{array}$ & $-0.17 \pm 0.16$ & $-0.33 \pm 0.15$ \\
\hline 3D_P 5 & -0.41 & -0.06 & -0.17 & -0.22 & $0.48 \pm 0.09$ & $.73 \leq 0.08$ & $-0.37 \pm 0.14$ & $\begin{array}{c}-0.01 \pm \\
0.16\end{array}$ & $\begin{array}{c}0.17 \pm \\
0.15\end{array}$ & $-0.01 \pm 0.16$ & $0.23 \pm 0.15$ \\
\hline 3D_P 6 & -0.49 & 0.15 & -0.16 & -0.19 & 156 & $0.66 \pm 0.09$ & $-0.25 \pm 0.15$ & $\begin{array}{c}0.44 \pm \\
0.12\end{array}$ & $\begin{array}{c}0.58 \pm \\
0.10\end{array}$ & $0.49 \pm 0.12$ & $0.69 \pm 0.08$ \\
\hline 3D_P 7 & 0.09 & 0.30 & 0.63 & 0.70 & -0.19 & 0.02 & $0.29 \pm 0.06$ & $\begin{array}{c}0.05 \pm \\
0.16\end{array}$ & $\begin{array}{c}-0.03 \pm \\
0.16\end{array}$ & $0.12 \pm 0.16$ & $-0.01 \pm 0.16$ \\
\hline Logr_hl-Carss & -0.23 & 0.65 & 0.21 & $\cap_{14}$ & 0.05 & -0.23 & 0.22 & $\begin{array}{c}0.46 \pm \\
0.08\end{array}$ & $\begin{array}{c}0.97 \pm \\
0.01\end{array}$ & $0.86 \pm 0.04$ & $0.85 \pm 0.05$ \\
\hline Logr_Fill & -0.38 & 0.54 & 0.04 & 7.01 & 0.19 & -0.38 & 0.17 & 0.77 & $\begin{array}{c}0.50 \pm \\
0.08\end{array}$ & $0.84 \pm 0.05$ & $0.88 \pm 0.04$ \\
\hline $\begin{array}{l}\text { 3DMod_hl- } \\
\text { Carss }\end{array}$ & -0.18 & 0.94 & 0. ' 0 & 0.20 & 0.05 & -0.18 & 0.30 & 0.70 & 0.60 & $0.46 \pm 0.08$ & $0.94 \pm 0.02$ \\
\hline 3DMod_Fil & -0.53 & 0.83 & J.12 & 0.08 & 0.26 & 0.53 & 0.26 & 0.66 & 0.67 & 0.90 & $0.56 \pm 0.09$ \\
\hline
\end{tabular}


Table 3: Genetic correlations \pm standard error between most informative simple predictors, 3D model-predicted yields and yield-related traits

\begin{tabular}{cccccc}
\hline & 3D_P & 3D_P & 3D_P & 3DMod_hl-Carss & 3DMod_Fil \\
\hline $\boldsymbol{r}_{\mathbf{g}}$ BW & $0.36 \pm 0.13$ & $-0.10 \pm 0.15$ & $-0.32 \pm 0.13$ & $-0.21 \pm 0.14$ & $-0.30 \pm 0.14$ \\
$\boldsymbol{r}_{\mathbf{g}}$ FC & $0.47 \pm 0.11$ & $-0.05 \pm 0.14$ & $-0.36 \pm 0.12$ & $-0.18 \pm 0.13$ & $-0.30 \pm 0.13$ \\
$\boldsymbol{r}_{\mathbf{g}}$ \% Fat & $-0.37 \pm 0.13$ & $0.37 \pm 0.13$ & $0.31 \pm 0.13$ & $0.43 \pm 0.13$ & $0.49 \pm 0.11$ \\
$\boldsymbol{r}_{\mathbf{g}}$ RelBH & $0.50 \pm 0.11$ & $-0.13 \pm 0.13$ & $-0.51 \pm 0.10$ & $-0.31 \pm 0.13$ & $-0.43 \pm 0.11$ \\
$\boldsymbol{r}_{\mathbf{g}}$ RelHL & $0.86 \pm 0.04$ & $-0.27 \pm 0.13$ & $-0.61 \pm 0.08$ & $-0.47 \pm 0.11$ & $-0.67 \pm 0.08$ \\
\hline
\end{tabular}


Table 4: Genetic gains (in percent body weight units) per generation with two selection intensities (\% selected - 10\%, 30\%) using mass (MS), full sib (FSS), and indirect (IS) selection for fillet yield improvement.

\begin{tabular}{cccc}
\hline Trait selected & Type of selection & Genetic gain (10\%) & Genetic gain (30\%) \\
\hline Logr_Fill & MS & 0.70 & 0.46 \\
Logr_Fill & FSS & 0.61 & 0.40 \\
3DMod_Fill & IS & 0.65 & 0.43 \\
3D_P1 & IS & 0.41 & 0.27 \\
3D_P2 & IS & 0.48 & 0.32 \\
3D_P & IS & 0.12 & 0.08 \\
3D_P & IS & 0.19 & 0.12 \\
3D_P & IS & 0.09 & 0.06 \\
3D_P & IS & 0.47 & 0.31 \\
3D_P & IS & 0.02 & 0.01 \\
2DMod_Fill & IS & 0.66 & 0.43 \\
2D_P $*$ & IS & 0.33 & 0.22 \\
2D_P $*$ & IS & 0.52 & 0.34 \\
\hline
\end{tabular}

* cited from Prchal et al., (2018a) 


\section{Figure Captions}

Figure 1: 3D landmarks place on each carp.

1: head extremity; 2: end of the head beginning of the fillet on the back; 3: intersection between opercula and lateral line; 4: opercula at the maximum length from the landmark 1; 5: end of the head beginning of the fillet on the ventral part; 6: beginning of the dorsal fin; 7: intersection between the lateral line and the vertical of landmark 6; 8: intersection of the ventral part and the vertical of point 7; 9: beginning of the anal fin; 10: intersection between lateral line and vertical of point 9 towards the carp back; 11: vertical of point 10 on the back; 12: end of anal fin; 13: intersection of lateral line and vertical of $12 ; 14$ : vertical of point 13 on the carp back; 25: end of the caudal fin at the fork.

Figure 2: A graphical visualization of body and ventral r...t t.orphology associated to low (blue line) and high (red line) yield for Logr_hl-Carss 'A, 3) and Logr_Fill (C, D) 
Figures

Figure 1

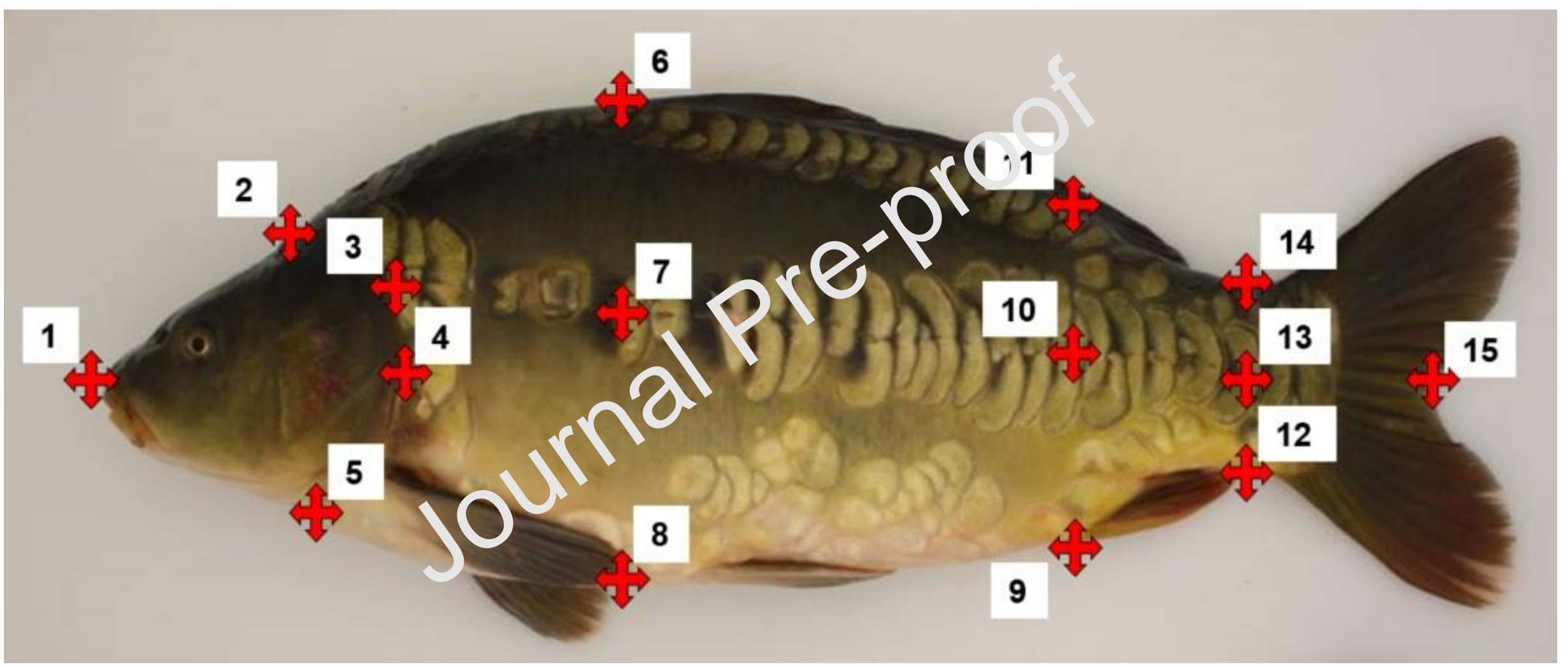


Figure 2A

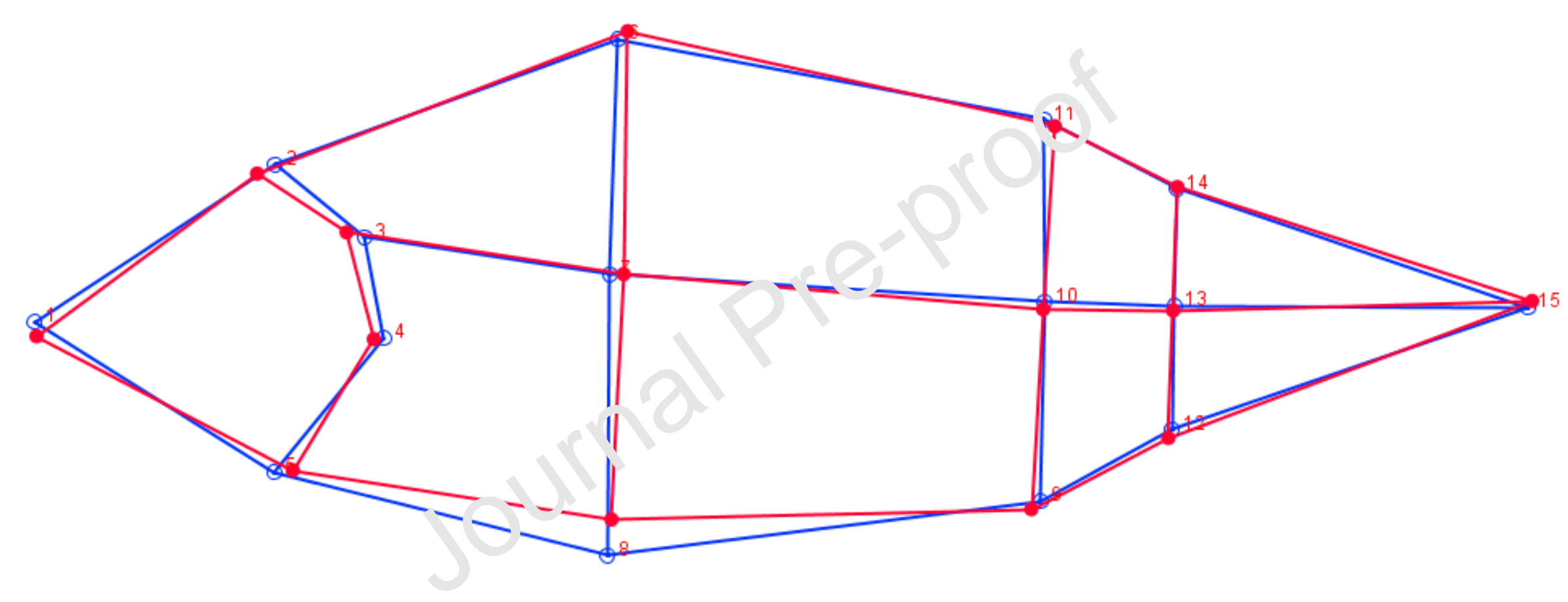




\section{Journal Pre-proof}

Figure 2B

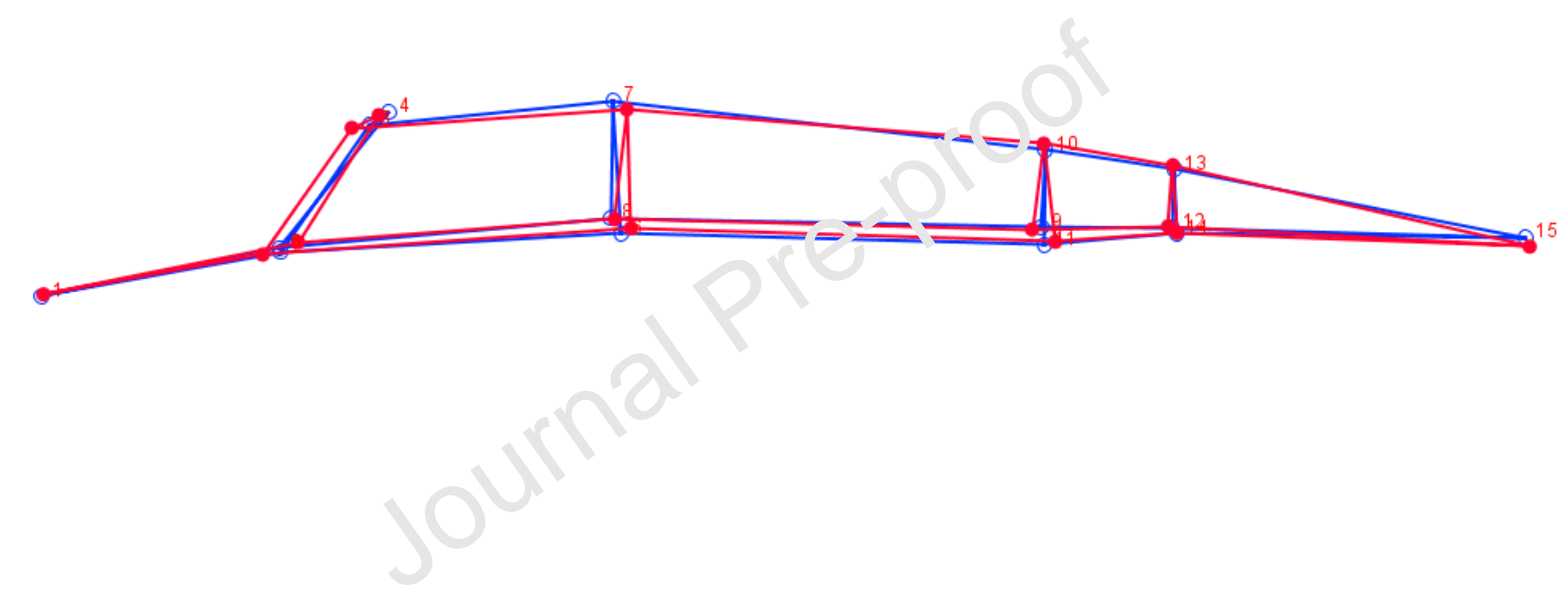


Figure 2C

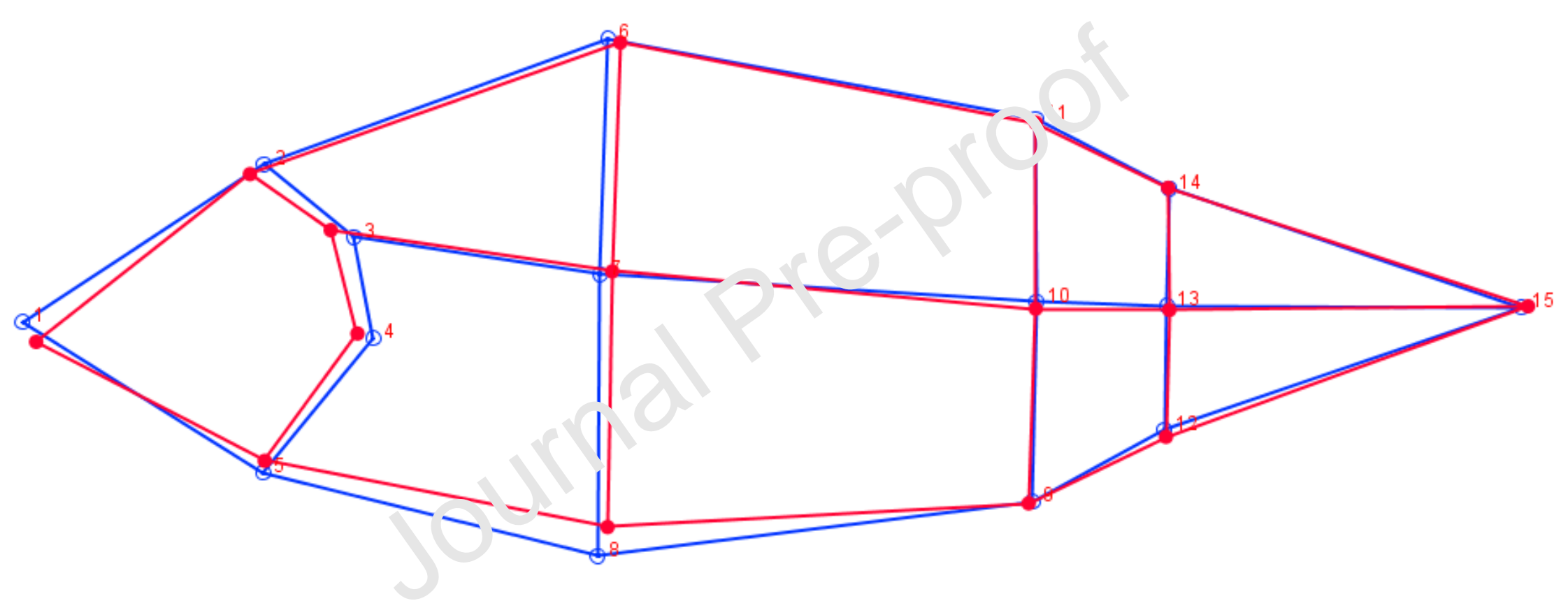


Figure 2D

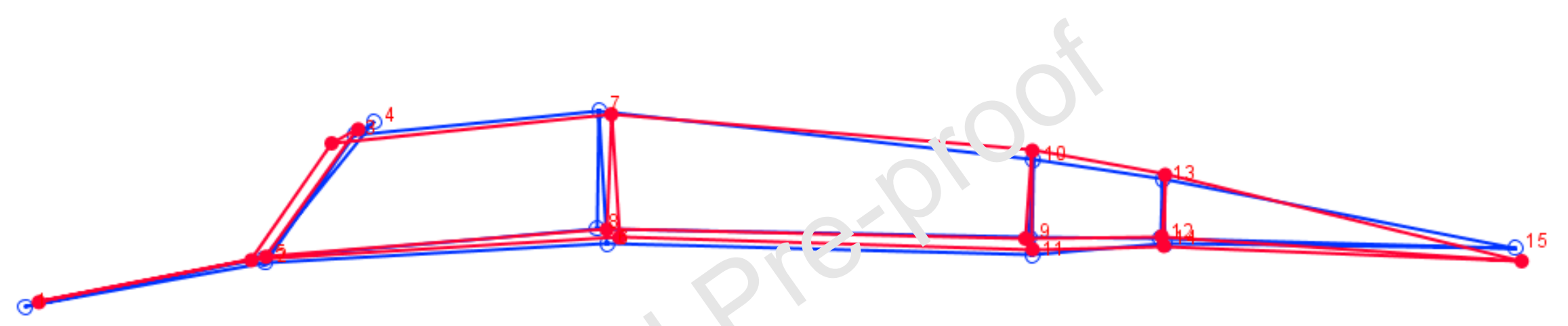


Highlights

- We studied combination of 3D digitized landmarks and ultrasound measurements

- 3D collection of morphol ogical landmarks do not imply post processing of images

- Genetic parameters of 3D model/simple predictors were solid

- Future carp breeding strategies have been suggested 